\title{
JOURNAL OF EASTERN
}

MEDITERRANEAN

\section{ARCHAEOLOGY AND HERITAGE STUDIES}

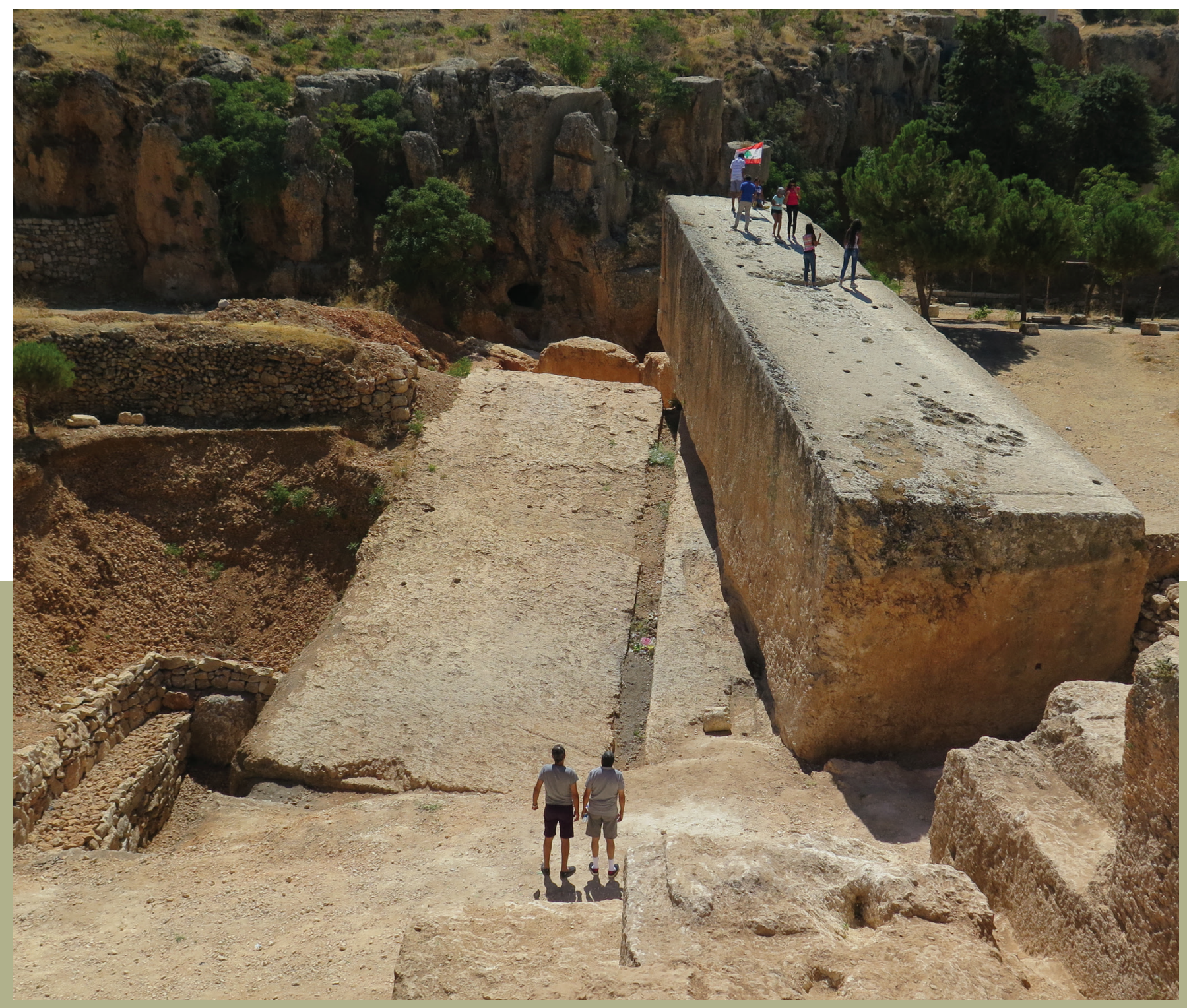




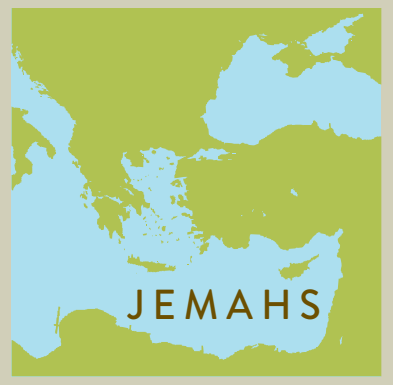

EDITORS

Ann E. Killebrew,

The Pennsylvania State University,

University Park (USA)

Sandra A. Scham,

The Catholic University of America (USA)

\section{ASSISTANT EDITORS}

Justin Lev-Tov,

Statistical Research, Inc. (USA)

Louise A. Hitchcock,

University of Melbourne

(Australia)

\section{BOOK REVIEW EDITOR}

Brandon R. Olson,

Boston University (USA)

\section{EDITORIAL ASSISTANT}

Heather D. Heidrich,

The Pennsylvania State

University, University Park (USA)

\section{EDITORIAL AND ADVISORY BOARD}

Lorenzo d'Alfonso, Institute for the Study of the Ancient World,

New York University (USA)

Mitch Allen, Mills College (USA)

Jere L. Bacharach, University of Washington (USA)

Hanan Charaf, University of Paris I-Sorbonne (France)

Yiorgos Chrysanthou, University of Cyprus (Cyprus)

Eric $\mathrm{H}$. Cline, The George Washington University (USA)

Elif Denel, American Research Institute in Turkey, Ankara (Turkey)

Hermann Genz, American University of Beirut (Lebanon) Ioannis Georganas, Independent Researcher (Greece)

Matthew Harpster, Institute of Nautical Archaeology, Bodrum (Turkey)
Kenneth G. Holum, University of Maryland at College Park (USA) Morag Kersel, DePaul University (USA)

Saleh Lamei, D. G. Centre for Conservation of Islamic Architectural Heritage (Egypt)

Mark Leone, University of Maryland at College Park (USA) Thomas E. Levy, University of California at San Diego (USA) Lynn Meskell, Stanford University (USA)

Mark Munn, The Pennsylvania State University, University Park (USA)

Mirko Novák, University of Bern (Switzerland)

Shelley-Anne Peleg, Israel Antiquities Authority (Israel) Issa Jubrael Sarie, Al-Quds University (Jerusalem)
Neil A. Silberman, University of Massachusetts Amherst (USA) Stuart Tyson Smith, University of California at Santa Barbara (USA)

Sharon R. Steadman, SUNY Cortland (USA)

Margreet Steiner, Independent Scholar (The Netherlands) Christopher A. Tuttle, Council of American Overseas Research Centers (USA)

Stephen Weiner, Weizmann Institute of Science (Israel) James M. Weinstein, Cornell University (USA) Donald Whitcomb, The University of Chicago (USA) 


\section{JOURNAL OF EASTERN MEDITERRANEAN \\ ARCHAEOLOGY AND \\ HERITAGE STUDIES}

VOL. $3 \quad$ NO. $4 \quad 2015$

iii From the Guest Editor

Hanan Charaf

FEATURE ARTICLES

313 The Megalithic Quarry of Baalbek: Sector III the Megaliths of Hajjar al-Ḥibla Jeanine Abdul Massih

330 Porphyreon through the Ages: The Fading Archaeological Heritage of the Lebanese Coast

Tomasz Waliszewski and Mariusz Gwiazda

349 Greco-Roman Burial Practices in the Bekaa Valley, Lebanon, and Its Adjacent Uplands

Paul Newson

372 Chhim, Lebanon: A Roman and Late Antique Village in the Sidon Hinterland

Tomasz Waliszewski and Urszula Wicenciak

396 Anfeh Unveiled: Historical Background, Ongoing Research, and Future Prospects

Nadine Panayot Haroun

416 Notes on the Archaeological Surface Survey of Qal'at 'Aïsha: The Highest Fortified Site in the Ancient Near East Anis Chaaya

NOTES ON A DISAPPEARING PAST

428 The Legacy of Fakhreddine II-Renaissance Prince of Mount Lebanon Sandra A. Scham 
THE JOURNAL OF EASTERN MEDITERRANEAN

ARCHAEOLOGY AND HERITAGE STUDIES (JEMAHS)

is a peer-reviewed journal published by The Pennsylvania State University Press. JEMAHS is devoted to traditional, anthropological, social, and applied archaeologies of the eastern Mediterranean, encompassing both prehistoric and historic periods. The journal's geographic range spans three continents and brings together, as no academic periodical has done before, the archaeologies of Greece and the Aegean, Anatolia, the Levant, Cyprus, Egypt, and North Africa.

As the journal will not be identified with any particular archaeological discipline, the editors invite articles from all varieties of professionals who work on the past cultures of the modern countries bordering the eastern Mediterranean Sea. Similarly, a broad range of topics will be covered including, but by no means limited to:

Excavation and survey field results;

Landscape archaeology and GIS;

Underwater archaeology;

Archaeological sciences and archaeometry;

Material culture studies;

Ethnoarchaeology;

Social archaeology;

Conservation and heritage studies;

Cultural heritage management;

Sustainable tourism development; and

New technologies/virtual reality.

Appearing four times a year in February, May, August, and November, the journal will engage professionals and scholars of archaeology and heritage studies as well as non-practitioners and students, both graduate and undergraduate.

In addition to combining traditional and theoretical archaeological data and interpretation, the journal's articles may range from early prehistory to recent historical time periods. It also aims to publish accessible, jargon-free, readable, color-illustrated articles that will be informative for professional and non-professional readers. The journal does not publish unprovenanced artifacts purchased on the antiquities market or objects from private collections.

\section{SUBMISSION INFORMATION}

Digital submissions should be sent to: www.editorialmanager.com/ JEMAHS. All correspondence should be sent to: Dr. Ann E. Killebrew (aek11@psu.edu). By submitting their work to JEMAHS, authors agree to editorial modifications of their manuscripts that are designed to help JEMAHS fulfill its mission.
Articles should be submitted as a MS Word file together with all illustrations (1200 dpi for black and white; 6oo dpi for grayscale; and at least 300 dpi for color) referenced in the manuscript. Permissions to use photographs and copyrights for all illustrations are the responsibility of the authors and need to be included when the manuscript is submitted. (For more information regarding copyright issues for authors, go to: http://psupress.org/author/ author_copyright.html). Papers should be limited to not more than 20-25 manuscript pages or ca. 6,000-7,000 words. Shorter papers are welcome, but authors wishing to submit a paper longer than 25 manuscript pages (including endnotes, references, and appendices) should consult with the editors in advance.

For complete author submission guidelines, please visit: http://www.psupress.org/journals/jnls_JEMAHS.html

\section{SUBSCRIPTION INFORMATION}

The Journal of Eastern Mediterranean Archaeology and Heritage Studies is published quarterly by The Pennsylvania State University Press, $820 \mathrm{~N}$. University Dr., USB 1, Suite C, University Park, PA 16802. Subscriptions, claims, and changes of address should be directed to our subscription agent, The Johns Hopkins University Press, P.O. Box 19966, Baltimore, MD 21211, phone 1-80o-548-1784 (outside USA and Canada: 410-5166987), jrnlcirc@press.jhu.edu. Subscribers are requested to notify The Johns Hopkins University Press and their local postmaster immediately of change of address. All correspondence of a business nature, including permissions and advertising, should be addressed to The Pennsylvania State University Press, www.psupress.org.

The Pennsylvania State University Press is a member of the Association of American University Presses.

\section{RIGHTS AND PERMISSION}

JEMAHS is registered under its ISSN (2166-3548 [E-ISSN 2166-3556]) with the Copyright Clearance Center, 222 Rosewood Drive, Danvers, MA 01923 (www.copyright.com). For information about reprints or multiple copying for classroom use, contact the CCC's Academic Permissions Service, or write to The Pennsylvania State University Press, 820 N. University Dr., USB 1, Suite C, University Park, PA 16802.

Copyright (c) 2015 by The Pennsylvania State University. All rights reserved. No copies may be made without the written permission of the publisher. 


\section{PORPHYREON THROUGH \\ THE AGES}

Tomasz Waliszewski

\section{The Fading Archaeological Heritage of the Lebanese Coast}

Mariusz Gwiazda

\section{ABSTRACT}

Ancient Porphyreon (Jiyeh/Nebi Younis) was a large rural settlement located on the coast of modern-day Lebanon, near the Phoenician city of Sidon. This article presents the initial research results of the stratigraphic data, extending from at least the eighth century $B C$ to the seventh century $\mathrm{AD}$, and explores how Phoenician village functioned. Analysis proves that it played a significant role in the local economy-on the one hand, providing for the city of Sidon and, on the other, mediating the exchange of goods with rural settlements, scattered across the mountainous hinterland. Uncovering the mysteries of this coastal settlement is extremely important, especially in light of the increasing threat to the archaeological heritage of Lebanon.

KEY WORDS : Phoenicia, rural settlement, Iron Age, Persian period, Greco-Roman period, Sidon

In about half an hour we passed over a small projecting point called Ras El Jeddra, and in a hour, we came to a similar tongue of land, called Ras el-Nebbionis, where there were some ruins of former buildings ... (Buckingham 1825: 435)

JOURNAL OF EASTERN MEDITERRANEAN ARCHAEOLOGY

AND HERITAGE STUDIES, VOL. 3, NO. 4, 2015

Copyright (C) 2015 The Pennsylvania State University, University Park, PA
The Phoenician coast between Beirut and Sidon is interspersed with numerous shallow bays from which mountainous promontories arise, similar to Ras el-Jedrah or Ras Nebi Younis mentioned by James Silk Buckingham when he traveled through the region in the early nineteenth century. The area is associated with the prophet Jonah who is believed to have been washed ashore here after being thrown overboard. This spot has also been described by European travelers such as Consul Clairambault who mentioned the existence of a village mosque associated with the prophet's weli ("tomb") and a khan for caravans to access to drinking water (Chahine 1989: 179) in 1767. Aside from Nebi Younis (Jonah), the archaeological site is also tied to Jiyeh, the name belonging to a settlement located to the north.

The ruins mentioned by travelers caught the interest of Frenchman Ernest Renan, who, between October 1860 and October 1861, led the first scientific archaeological exploration of Phoenicia. He was the first to associate the site with the town of Porphyreon mentioned by ancient writers (Renan 1864: 513) and discovered walls covered in paintings as well as a chapel filled with mosaic floors. From that moment onward, explorations of this rich archaeological site continued, divided into stages due to the dramatic events that Lebanon witnessed during the twentieth century.

In the spring of 1914, French archaeologist Georges Contenau conducted research at Jiyeh and discovered an 